\title{
Influência da temperatura e do ácido ascórbico sobre a estabilidade físico-química e atividade enzimática da água de coco (Cocos nucifera $\mathbf{L}$.) acondicionada assepticamente
}

\author{
Temperature and ascorbic acid effects in physico-chemical stability and
} enzimatic activity of coconut water (Cocos nucifera L.) aseptic filled

\author{
Laura Figueiredo ABREU ${ }^{1}$, José de Assis Fonseca FARIA ${ }^{2 *}$
}

\begin{abstract}
Resumo
Este estudo teve por objetivo avaliar a estabilidade físico-química da água de coco quando processada termicamente entre 138 e $144{ }^{\circ} \mathrm{C}$ por 10 segundos, com adição de ácido ascórbico nas concentrações de 0,100 e $200 \mathrm{mg}$. $\mathrm{L}^{-1}$. Foram processados cinco lotes de água de coco em pequena escala, fazendo-se a avaliação de sua estabilidade por três meses. O tratamento térmico a $139{ }^{\circ} \mathrm{C} / 10$ segundos e o uso de $200 \mathrm{mg.L} \mathrm{L}^{-1}$ de ácido ascórbico foram consideradas as melhores condições de processo para manter a estabilidade físico-química da água de coco esterilizada e acondicionada assepticamente.

Palavras-chave: água de coco; esterilização; ácido ascórbico; sistema asséptico; enzima.
\end{abstract}

\begin{abstract}
This study had the objective to test stability of coconut water (Cocos nucifera) during the process and storage. The process conditions were temperatures ranging from 138 to $144{ }^{\circ} \mathrm{C}$ under holding time of 10 seconds. Five batches of coconut water containing 0 , 100 and $200 \mathrm{mg} . \mathrm{L}^{-1}$ of ascorbic acid were processed and filled aseptically in glass tubes. The treatment which had more stability was the one done at $139{ }^{\circ} \mathrm{C} / 10$ seconds containing $200 \mathrm{mg} . \mathrm{L}^{-1}$ of ascorbic acid.

Keywords: coconut water; sterilization; ascorbic acid; aseptic system; enzyme.
\end{abstract}

\section{Introdução}

O Brasil produz cerca de 500 milhões de litros de água de coco por ano, sendo que $7 \%$ deste total é destinado à exportação ${ }^{4}$. O surgimento de uma coloração rosada durante a estocagem é o grande problema encontrado pelos envasadores e exportadores de água de $\operatorname{coco}^{3,4,6,26}$. Este segmento de mercado está em franca ascensão (3,6 milhões L/ano) e justifica o desenvolvimento tecnológico em engenharia e controle de processos $^{10}$. A água de coco vem sendo comercializada em garrafas de polietileno tereftalato (PET), resfriadas $\left(0-10{ }^{\circ} \mathrm{C}\right)$ e congeladas $\left(-18{ }^{\circ} \mathrm{C}\right)$, utilizando cocos verdes da variedade anã - em embalagens cartonadas à temperatura ambiente e utilizando cocos maduros da variedade híbrida ${ }^{19,24}$. A água de coco acondicionada em embalagens cartonadas tem a vantagem de comercialização à temperatura ambiente, possibilitada pelo tratamento térmico com ultra-alta temperatura (UAT), seguido de acondicionamento asséptico. Entretanto, além do tratamento térmico, é utilizado o conservador metabissulfito de sódio para evitar o escurecimento devido às enzimas polifenoloxidase e peroxidase $^{26}$. Porém, a sua utilização pode acarretar perda nutricional e sensorial no produto, além de indícios de que pode causar reações alérgicas em indivíduos sensíveis aos sulfitos ${ }^{3,7,8,23,27,30}$. O ácido ascórbico (AA) é considerado uma

\footnotetext{
Recebido para publicação em 5/9/2005

Aceito para publicação em 23/4/2007 (001606)

${ }^{\prime}$ Departamento de Tecnologia de Alimentos,

Faculdade de Engenharia de Alimentos,

Universidade Estadual de Campinas - UNICAMP,

E-mail:laura@cpatu.embrapa.br

Departamento de Tecnologia de Alimentos,

Faculdade de Engenharia de Alimentos,

Universidade Estadual de Campinas - UNICAMP,

Rua Monteiro Lobato, 80, CP 6121, CEP 13083-862, Campinas - SP, Brasil,

E-mail: assis@fea.unicamp.br

* A quem a correspondencia deve ser enviada
}

das melhores alternativas para o uso dos sulfitos, por ser altamente efetivo contra o escurecimento enzimático, possuindo, entretanto, uma menor estabilidade e menor velocidade de redução do oxigênio ${ }^{27}$. $\mathrm{ABREU}^{2}$ recomenda seu uso para estabilização química da água de coco. A tecnologia de sistemas assépticos consiste no acondicionamento de um produto comercialmente estéril em uma embalagem pré-esterilizada, em um ambiente controlado ou em áreas limpas, seguido de um fechamento asséptico e hermético. Este procedimento permite estocagem e comercialização à temperatura ambiente e uma maior preservação da qualidade do produto ${ }^{5,13,18,25}$, mas devido à complexidade dessa tecnologia, é necessário um alto investimento ${ }^{5,25}$. No caso da água de coco, somente as grandes empresas processadoras de coco maduro utilizam o sistema asséptico, cuja água é um subproduto da industrialização da amêndoa ${ }^{24}$. Entretanto, os maiores envasadores de água de coco verde são as pequenas e médias empresas. Por este motivo, um sistema asséptico piloto foi idealizado por FARIA ${ }^{14}$ visando fornecer esta tecnologia com menor custo operacional e para fins de produção de diferentes bebidas comercialmente estéreis, acondicionadas em embalagens plásticas. Nesta pesquisa utilizou-se o sistema asséptico piloto desenvolvido por Faria para avaliar a estabilidade físico-química da água de coco processada com diferentes temperaturas e concentrações de AA e acondicionada assepticamente em recipientes de vidro.

\section{Material e métodos}

\subsection{Extração da água de coco e formulação}

A água de coco foi extraída de cocos verdes da variedade anã, obtidos da CEASA da cidade de Campinas - SP. Os cocos 
foram previamente higienizados por aspersão com água e por imersão em solução de hipoclorito com 200 mg.L $\mathrm{L}^{-1}$ de cloro ativo por 20 minutos. O excesso foi retirado por imersão em água com $5 \mathrm{mg} . \mathrm{L}^{-1}$ de cloro. Os cocos foram previamente resfriados em câmara fria $\mathrm{a}-18{ }^{\circ} \mathrm{C}$ por 16 horas. A água de coco foi extraída com auxílio de extrator desenvolvido por FARIA ${ }^{15}$, o qual retirou a água do fruto com auxílio de ar comprimido. Previamente, a formulação da água de coco foi ajustada para 6,0 ${ }^{\circ}$ Brix e pH 4,94 com frutose e ácido cítrico, respectivamente. O AA foi adicionado imediatamente antes do tratamento térmico nas proporções indicadas por planejamento experimental.

A água de coco de cada lote foi acondicionada assepticamente em tubos $(70 \mathrm{~mL}$ ) de vidro de tampa rosqueável. Os tubos foram esterilizados em autoclave a $121{ }^{\circ} \mathrm{C} / 15$ minutos.

\subsection{Unidade de esterilização e sistema de acondicionamento asséptico}

A unidade de esterilização utilizada foi montada na Planta Piloto de Frutas do Departamento de Tecnologia de Alimentos da Faculdade de Engenharia de Alimentos da UNICAMP (DTA/ FEA/UNICAMP). A água de coco foi esterilizada em trocador de calor de ultra-alta temperatura (UAT), do tipo placa, com vazão nominal de 300 L/hora, fabricado por SUMÁ Indústria e Comércio Ltda, em Campinas-SP e composto pelas seções de regeneração, aquecimento do produto, aquecimento da água (meio de aquecimento), retenção, resfriamento do produto final (opção de água refrigerada) e resfriamento do produto retornado.

O sistema de acondicionamento asséptico foi montado dentro de uma sala limpa certificada do tipo ISO classe 7 ( $\geq 352.000$ partículas de $0,5 \mu \mathrm{m} . \mathrm{m}^{-3}$ de ar). A certificação foi feita conforme as normas e padrões internacionais, controlando-se a pressão positiva, a temperatura, a umidade relativa, o número de renovações de ar por hora e a contagem de microrganismos e partículas em suspensão ${ }^{22}$. A água de coco de cada lote, foi recolhida a $10{ }^{\circ} \mathrm{C}$ em erlenmeyers e foi distribuída em 25 tubos de vidro, ambos esterilizados.

\subsection{Processamento térmico e adição de ácido ascórbico}

A influência da temperatura de processo, juntamente com a concentração de AA, foi avaliada executando-se o planejamento experimental descrito na Tabela 1 . Como os cinco lotes foram processados consecutivamente, a ordem de processamento obedeceu ao aumento gradativo da temperatura do esterilizador UAT.

Tabela 1. Planejamento experimental de temperatura $x$ concentração de ácido ascórbico.

\begin{tabular}{ccc}
\hline Lote & Temperatura $\left({ }^{\circ} \mathrm{C}\right)^{*}$ & Ácido ascórbico $\left(\mathrm{mg} \cdot \mathrm{L}^{-1}\right)$ \\
\hline 1 & 138 & 0 \\
2 & 139 & 200 \\
3 & 141 & 100 \\
4 & 144 & 0 \\
5 & 144 & 200 \\
\hline${ }^{*}$ Com 10 segundos de retenção.
\end{tabular}

\subsection{Análises físico-químicas}

Durante a estocagem foram realizadas análises de $\mathrm{pH}$, AA, variação de cor e oxigênio dissolvido, conforme descrito a seguir:

As análises foram realizadas na água de coco in natura, formulada, processada (24 horas após o processamento térmico) e após 3, 5, 12 e 93 dias.

$\mathrm{O}$ pH foi medido a $25{ }^{\circ} \mathrm{C}$, utilizando-se potenciômetro da marca Digimed, modelo DM-20.

A concentração de ácido ascórbico foi determinada por titulação com 2,6 dicloroindofenol (DCFI), segundo metodologia descrita por SILVA ${ }^{28}$. Este método determinou somente o teor de AA não oxidado.

As medidas de cor foram realizadas em Colorímetro HunterLab, modelo ColorQUEST ${ }^{20}$. Utilizou-se o sistema de cor CIELAB, com iluminante D65, ângulo do observador de $10^{\circ}$ e calibração do tipo TTRAN. As amostras foram analisadas em três repetições, sendo colocadas em cubeta de quartzo de $10 \mathrm{~mm}$ de caminho óptico. Para as medidas de cor, foram determinados os seguintes parâmetros: $L^{*}$ - Luminosidade, que varia de 0 (preto) a 100 (branco); $\mathrm{a}^{*}$ - cromaticidade, que varia de $+a^{*}$ (vermelho) a -a*(verde); e b* - cromaticidade, que varia de $+\mathrm{b}^{*}$ (amarelo) a $-\mathrm{b}^{*}$ (azul). A partir destes parâmetros foi calculada a variação de cor $\Delta \mathrm{E}$ com o tempo de estocagem, utilizando-se como o padrão de cor inicial a água de coco in natura.

O oxigênio dissolvido na água de coco foi determinado com medidor de $\mathrm{O}_{2}$ dissolvido, TOLEDO METTLER, modelo MO128. Os resultados foram expressos em porcentagem (\%), em relação ao oxigênio no ar atmosférico.

\subsection{Atividade enzimática}

Para determinar a atividade das enzimas polifenoloxidase e peroxidase, foi utilizada uma adaptação da metodologia de $\operatorname{CAMPOS}^{7,8}$. A atividade da enzima polifenoloxidase foi determinada adicionando-se em uma cubeta $2,3 \mathrm{~mL}$ de tampão fosfato $(0,2 \mathrm{M})$ com $\mathrm{pH} 6,0,0,7 \mathrm{~mL}$ de catecol $(0,2 \mathrm{M})$ e $1 \mathrm{~mL}$ de amostra de água de coco, à temperatura ambiente $\left(25^{\circ} \mathrm{C}\right)$, seguido de leitura de absorvância em espectrofotômetro a $425 \mathrm{~nm}$, no tempo zero e após 10 minutos.

Para análise da atividade da enzima peroxidase, em uma cubeta foram adicionados $2,3 \mathrm{~mL}$ de tampão fosfato $(0,2 \mathrm{M})$ com pH 5,5, levando-se ao banho de água até atingir $35^{\circ} \mathrm{C}$. Posteriormente, adicionou-se $1 \mathrm{~mL}$ de água de coco, 0,2 mL de peróxido de hidrogênio $(0,1 \%)$ e $0,5 \mathrm{~mL}$ de solução alcoólica de guaiacol $(0,5 \%)$, agitou-se e fez-se leitura imediata em espectrofotômetro a $470 \mathrm{~nm}$, no tempo zero e após 10 minutos. A cubeta retornou ao banho de água até completar o tempo de reação.

Para análise das duas enzimas, utilizou-se como branco a mistura de todos os reagentes, substituindo-se a água de coco por água destilada. Foram utilizadas cubetas descartáveis de poliestireno de $4 \mathrm{~mL}$ e $10 \mathrm{~mm}$ de caminho óptico. A atividade foi expressa em unidades/mL.minuto. Uma unidade equivale a 
uma variação de 0,001 na absorvância por minuto por mL de amostra. Para o cálculo de atividade, utilizou-se a seguinte equação:

$\operatorname{Atividade}\left(\mathrm{U} \cdot \mathrm{mL}^{-1}\right)=\frac{\left(\mathrm{AF}_{\text {amostra }}-\mathrm{AI}_{\text {amostra }}\right)-\left(\mathrm{AF}_{\text {branco }}-\mathrm{AI}_{\text {branco }}\right)}{0,001 \times \mathrm{t}}$

onde, $\mathrm{AF}_{\text {amostra }}$ é a absorvância final da amostra, $\mathrm{AI}_{\text {amostra }}$ é a absorvância inicial da amostra, $\mathrm{AF}_{\text {branco }}$ é a absorvância final do branco, $\mathrm{AI}_{\text {branco }}$ é a absorvância inicial do branco e t é o tempo em minutos.

\section{Resultados e discussão}

\subsection{Análises físico-químicas}

Na Tabela 2 estão apresentados os resultados das análises físico-químicas dos cinco lotes de água de coco, e nas Figuras 1,
2 e 3 , a representação gráfica dos resultados considerados mais importantes.

A alteração mais marcante foi a variação de cor da água de coco. Observou-se que logo após a saída do trocador de calor, a água de coco dos Lotes 1 e 4 (sem ácido ascórbico) apresentou variação de cor superior à água de coco dos demais lotes, que possuía AA na sua formulação, sendo observada uma coloração rosa intensa.

Os resultados da Figura 1 indicaram que, sem a adição de AA a água de coco apresenta coloração rosada assim que passa por um tratamento térmico da magnitude dos aplicados neste experimento.

Esta coloração rosada é comum em águas de coco in natura, ou quando armazenadas por alguns dias sob refrigeração $0^{1,4,6,9,11,12}$. Esta coloração foi observada nos estudos realizados pela FAO, utilizando-se ultrafiltração, na qual foi

Tabela 2. Análises físico-químicas da água de coco*.

\begin{tabular}{|c|c|c|c|c|c|}
\hline Lote & Tempo (dias) & $\Delta \mathrm{E}$ & $\mathrm{AA}$ & $\mathrm{O}_{2}$ & $\mathrm{pH}$ \\
\hline \multirow{7}{*}{$\begin{array}{l}1 \\
\left(138^{\circ} \mathrm{C}\right)\end{array}$} & In natura & $0,00 \pm 0,00$ & $9,65 \pm 0,88$ & $8,02 \pm 0,38$ & $5,20 \pm 0,00$ \\
\hline & Formulada & $0,07 \pm 0,02$ & $9,65 \pm 0,88$ & $8,02 \pm 0,38$ & $4,98 \pm 0,00$ \\
\hline & Processada & $1,44 \pm 0,04$ & $7,02 \pm 1,75$ & $4,85 \pm 0,86$ & $4,98 \pm 0,01$ \\
\hline & 3 & $3,06 \pm 0,06$ & $6,14 \pm 0,88$ & $4,43 \pm 0,19$ & $4,98 \pm 0,01$ \\
\hline & 5 & $3,28 \pm 0,02$ & $3,51 \pm 0,00$ & $4,59 \pm 0,30$ & $4,95 \pm 0,00$ \\
\hline & 12 & $3,95 \pm 0,04$ & $1,75 \pm 0,00$ & $4,68 \pm 0,25$ & $4,95 \pm 0,01$ \\
\hline & 93 & $4,90 \pm 0,02$ & $1,24 \pm 0,88$ & $3,62 \pm 0,22$ & $4,93 \pm 0,00$ \\
\hline \multirow{7}{*}{$\begin{array}{l}2 \\
\left(139^{\circ} \mathrm{C}\right)\end{array}$} & In natura & $0,00 \pm 0,00$ & $9,65 \pm 0,88$ & $8,02 \pm 0,38$ & $5,20 \pm 0,00$ \\
\hline & Formulada & $0,11 \pm 0,02$ & $219,25 \pm 8,77$ & $8,09 \pm 0,01$ & $4,92 \pm 0,01$ \\
\hline & Processada & $0,20 \pm 0,04$ & $184,17 \pm 0,00$ & $3,65 \pm 0,50$ & $4,91 \pm 0,01$ \\
\hline & 3 & $0,88 \pm 0,02$ & $144,71 \pm 4,39$ & $2,12 \pm 0,04$ & $4,90 \pm 0,00$ \\
\hline & 5 & $0,96 \pm 0,02$ & $135,94 \pm 4,39$ & $0,86 \pm 0,23$ & $4,86 \pm 0,00$ \\
\hline & 12 & $1,58 \pm 0,02$ & $96,47 \pm 0,00$ & $0,25 \pm 0,06$ & $4,87 \pm 0,00$ \\
\hline & 93 & $2,37 \pm 0,04$ & $91,60 \pm 0,00$ & $0,21 \pm 0,08$ & $4,87 \pm 0,00$ \\
\hline \multirow{7}{*}{$\begin{array}{l}3 \\
\left(141^{\circ} \mathrm{C}\right)\end{array}$} & In natura & $0,00 \pm 0,00$ & $9,65 \pm 0,88$ & $8,02 \pm 0,38$ & $5,20 \pm 0,00$ \\
\hline & Formulada & $0,11 \pm 0,02$ & $98,02 \pm 4,39$ & $7,94 \pm 0,59$ & $4,96 \pm 0,01$ \\
\hline & Processada & $0,28 \pm 0,04$ & $83,32 \pm 4,39$ & $3,13 \pm 0,60$ & $4,96 \pm 0,01$ \\
\hline & 3 & $0,90 \pm 0,06$ & $52,62 \pm 0,00$ & $1,51 \pm 0,59$ & $4,96 \pm 0,00$ \\
\hline & 5 & $1,09 \pm 0,02$ & $48,24 \pm 4,39$ & $0,61 \pm 0,20$ & $4,90 \pm 0,01$ \\
\hline & 12 & $1,99 \pm 0,02$ & $35,08 \pm 0,00$ & $0,53 \pm 0,21$ & $4,91 \pm 0,00$ \\
\hline & 93 & $6,60 \pm 0,04$ & $9,88 \pm 0,00$ & $0,42 \pm 0,25$ & $4,92 \pm 0,00$ \\
\hline \multirow{7}{*}{$\begin{array}{l}4 \\
\left(144^{\circ} \mathrm{C}\right)\end{array}$} & In natura & $0,00 \pm 0,00$ & $9,65 \pm 0,88$ & $8,02 \pm 0,38$ & $5,20 \pm 0,00$ \\
\hline & Formulada & $0,07 \pm 0,02$ & $9,65 \pm 0,88$ & $8,93 \pm 0,53$ & $5,00 \pm 0,00$ \\
\hline & Processada & $2,35 \pm 0,04$ & $6,14 \pm 0,88$ & $4,79 \pm 0,59$ & $5,00 \pm 0,01$ \\
\hline & 3 & $2,66 \pm 0,02$ & $3,51 \pm 0,88$ & $4,37 \pm 0,25$ & $5,00 \pm 0,00$ \\
\hline & 5 & $3,42 \pm 0,02$ & $1,75 \pm 0,00$ & $4,39 \pm 0,90$ & $4,94 \pm 0,00$ \\
\hline & 12 & $3,74 \pm 0,04$ & $1,75 \pm 0,00$ & $4,30 \pm 0,32$ & $4,96 \pm 0,00$ \\
\hline & 93 & $5,99 \pm 0,02$ & $1,24 \pm 0,00$ & $1,20 \pm 0,32$ & $4,93 \pm 0,01$ \\
\hline \multirow{7}{*}{$\begin{array}{l}5 \\
\left(144^{\circ} \mathrm{C}\right)\end{array}$} & In natura & $0,00 \pm 0,02$ & $9,65 \pm 0,88$ & $8,02 \pm 0,38$ & $5,20 \pm 0,00$ \\
\hline & Formulada & $0,07 \pm 0,02$ & $214,87 \pm 4,39$ & $8,44 \pm 0,69$ & $4,95 \pm 0,01$ \\
\hline & Processada & $0,43 \pm 0,02$ & $157,86 \pm 8,77$ & $3,61 \pm 0,42$ & $4,93 \pm 0,01$ \\
\hline & 3 & $1,16 \pm 0,02$ & $127,17 \pm 4,39$ & $1,41 \pm 0,19$ & $4,92 \pm 0,01$ \\
\hline & 5 & $1,37 \pm 0,04$ & $122,78 \pm 0,00$ & $0,44 \pm 0,19$ & $4,88 \pm 0,01$ \\
\hline & 12 & $2,53 \pm 0,06$ & $87,70 \pm 0,00$ & $0,32 \pm 0,13$ & $4,88 \pm 0,00$ \\
\hline & 93 & $14,27 \pm 0,06$ & $6,80 \pm 0,00$ & $0,00 \pm 0,00$ & $4,86 \pm 0,00$ \\
\hline
\end{tabular}

${ }^{*}$ Média de três amostras; AA - ácido ascórbico (mg..-1 $)$; $\mathrm{O}_{2}$ - oxigênio dissolvido (\%); $\Delta \mathrm{E}$ - variação de cor. (Lote $1=138^{\circ} \mathrm{C} / 10$ segundos e sem adição de AA; Lote $2=139{ }^{\circ} \mathrm{C} / 10$ segundos $200 \mathrm{mg} \cdot \mathrm{L}^{-1}$ de AA; Lote $3=141^{\circ} \mathrm{C} / 10$ segundos e $100 \mathrm{mg} \cdot \mathrm{L}^{-1}$ de AA; Lote $4=144^{\circ} \mathrm{C} / 10$ segundos e sem adição de AA; Lote $5=144^{\circ} \mathrm{C} / 10$ segundos e $200 \mathrm{mg} \cdot \mathrm{L}^{-1}$ de AA; e AA = ácido ascórbico). 


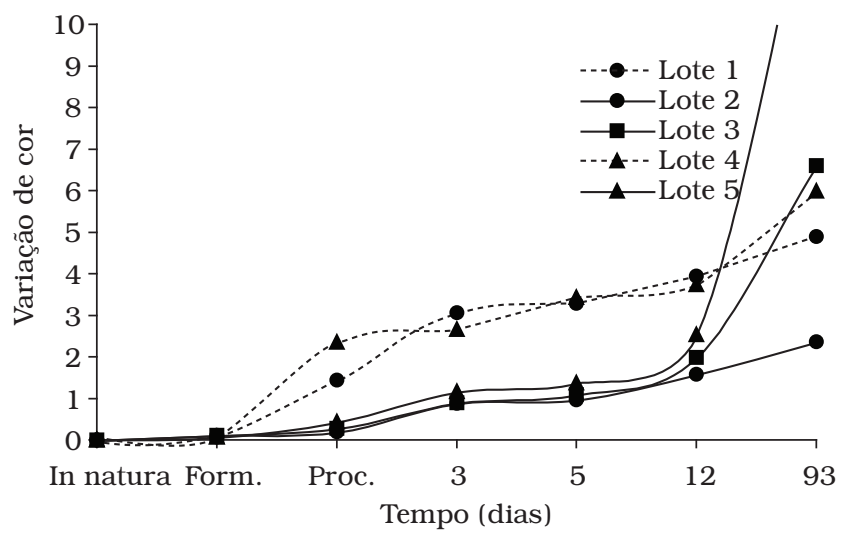

Figura 1. Variação de cor $(\Delta \mathrm{E})$ com o tempo de estocagem da água de coco (Lote $1=138^{\circ} \mathrm{C} / 10$ segundos e sem adição de AA; Lote $2=139^{\circ} \mathrm{C} /$ 10 segundos e $200 \mathrm{mg} \cdot \mathrm{L}^{-1}$ de AA; Lote $3=141^{\circ} \mathrm{C} / 10$ segundos e $100 \mathrm{mg} \cdot \mathrm{L}^{-1}$ de AA; Lote $4=144{ }^{\circ} \mathrm{C} / 10$ segundos e sem adição de AA; Lote $5=144{ }^{\circ} \mathrm{C} / 10$ segundos e $200 \mathrm{mg} \cdot \mathrm{L}^{-1}$ de AA; e AA = ácido ascórbico).

recomendado o uso de $150 \mathrm{mg} . \mathrm{L}^{-1}$ de AA para que esta alteração de cor não ocorresse ${ }^{12}$.

Um tratamento térmico intenso, sem a adição de um antioxidante como o AA, acelera as reações de alteração de cor que são naturais da água de coco.

Durante a estocagem, observou-se que todas as águas de coco tiveram um escurecimento progressivo. Entretanto, a água de coco do Lote 5 apresentou um escurecimento mais intenso. Como foi a água de coco processada na maior temperatura, de $144{ }^{\circ} \mathrm{C}$, atribui-se este maior escurecimento à maior degradação térmica do AA.

Esta hipótese pode ser reforçada, observando-se o comportamento das curvas de variação de concentração de AA apresentadas na Figura 2. A maior degradação de AA no $93^{\circ}$ dia de estocagem foi a do Lote 5, enquanto que a menor foi a do Lote 2 , que também teve a menor variação de cor $\Delta \mathrm{E}$ e a menor temperatura de processo $\left(139^{\circ} \mathrm{C}\right)$.

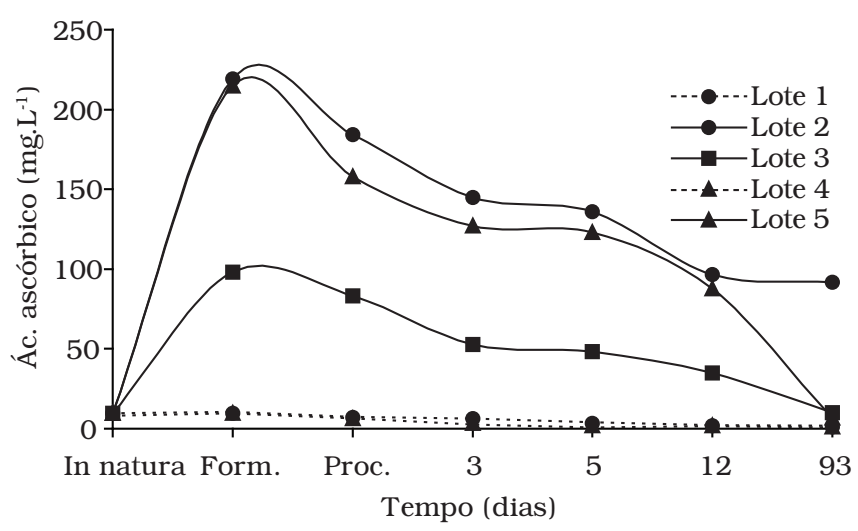

Figura 2. Concentração de ácido ascórbico com o tempo de estocagem da água de coco (Lote $1=138{ }^{\circ} \mathrm{C} / 10$ segundos e sem adição de AA; Lote $2=139{ }^{\circ} \mathrm{C} / 10$ segundos e $200 \mathrm{mg} \cdot \mathrm{L}^{-1}$ de AA; Lote $3=$ $141{ }^{\circ} \mathrm{C} / 10$ segundos e $100 \mathrm{mg} \cdot \mathrm{L}^{-1}$ de AA; Lote $4=144{ }^{\circ} \mathrm{C} / 10$ segundos e sem adição de AA; Lote $5=144^{\circ} \mathrm{C} / 10$ segundos e $200 \mathrm{mg} \cdot \mathrm{L}^{-1}$ de AA; e $\mathrm{AA}=$ ácido ascórbico).
Estes resultados podem ser relacionados também ao consumo de oxigênio dissolvido durante a estocagem, demonstrado na Figura 3. Nos lotes de água de coco em que houve adição de AA (Lotes 2, 3 e 5), a maior parte do oxigênio foi consumida após o $12^{\circ}$ dia de estocagem, o mesmo período em que a concentração de ácido ascórbico do Lote 2 praticamente estabilizou em 90 mg.L $\mathrm{L}^{-1}$.

Segundo NIELSEN, MARCY e SADLER ${ }^{21}$, o AA é uma molécula estável, entretanto, na presença de oxigênio ocorre a formação do ácido dehidroascórbico (DHAA), que é um composto termosensível. Durante a quebra do DHAA há a formação de substâncias como dióxido de carbono, ácido oxálico, ácido tartárico, ácido furóico, peróxido de hidrogênio e hidroximetilfurfural (HMF), além de outros componentes responsáveis pelo escurecimento ${ }^{16,17}$.

Foi observada também uma pequena, mas progressiva redução do pH durante a estocagem, a qual pode ser relacionada aos compostos ácidos provenientes da reação de gradação do AA e escurecimento, citados anteriormente ${ }^{17}$.

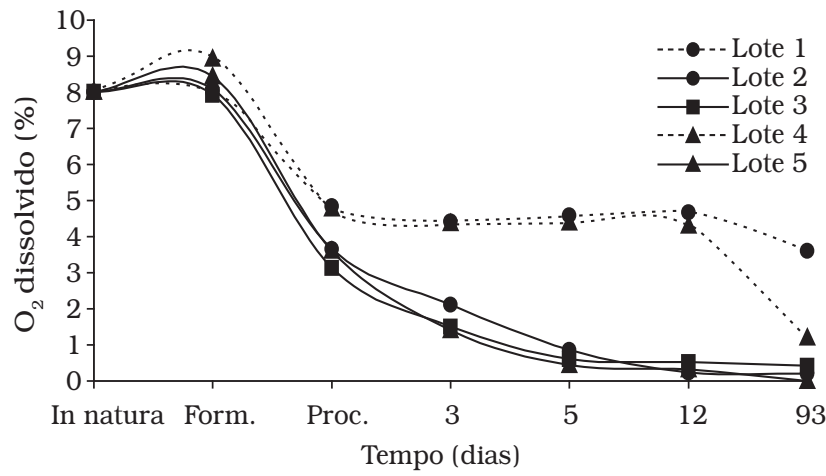

Figura 3. Oxigênio dissolvido com o tempo de estocagem da água de $\operatorname{coco}\left(\right.$ Lote $1=138^{\circ} \mathrm{C} / 10$ segundos e sem adição de AA; Lote $2=139{ }^{\circ} \mathrm{C} /$ 10 segundos e $200 \mathrm{mg} \cdot \mathrm{L}^{-1}$ de AA; Lote $3=141{ }^{\circ} \mathrm{C} / 10$ segundos e 100 mg. $\mathrm{L}^{-1}$ de AA; Lote $4=144{ }^{\circ} \mathrm{C} / 10$ segundos e sem adição de AA; Lote $5=144^{\circ} \mathrm{C} / 10$ segundos e $200 \mathrm{mg} \cdot \mathrm{L}^{-1}$ de $\mathrm{AA}$; e $\mathrm{AA}=$ ácido ascórbico).

\subsection{Atividade enzimática}

A água de coco in natura apresentou 2,33 U.mL ${ }^{-1}$ de polifenoloxidase. A água de coco formulada dos Lotes $2,3 \mathrm{e}$ 5 , na qual houve adição de $\mathrm{AA}$, não apresentou atividade de polifenoloxidase, enquanto que na água de coco formulada dos Lotes 1 e 4, em que foi adicionado somente ácido cítrico, observou-se 1,82 U.mL $\mathrm{mL}^{-1}$ e 1,39 U.mL ${ }^{-1}$ de polifenoloxidase, respectivamente. Ou seja, a adição de AA foi eficaz na inativação da polifenoloxidase, antes do tratamento térmico. Após o tratamento térmico, não foi detectada atividade em nenhum dos cinco lotes produzidos.

A adição de ácido cítrico causou na água de coco dos Lotes 1 e 4 uma redução de atividade de $21,89 \%$ e de $59,66 \%$, respectivamente. CAMPOS $^{7,8}$ observou uma redução de $26,8 \%$ com $148 \mathrm{mg} .100 \mathrm{~mL}^{-1}$ de ácido cítrico (96 mg adicionados + $55 \mathrm{mg}$ da água de coco), apresentando pH 4,30. Em pH 4,90 , Campos observou uma redução de $7 \%$ na atividade, o 
que correspondeu a $62 \mathrm{mg} .100 \mathrm{~mL}^{-1}$ de ácido cítrico. Na água de coco dos Lotes 1 e 4 havia o equivalente a $66 \mathrm{mg} 100 \mathrm{~mL}^{-1}$ de ácido cítrico, contudo, encontrou-se uma inativação maior, isto pode ser explicado pela baixa atividade de PPO encontrada na água de coco utilizada neste experimento de 2,33 U.mL ${ }^{-1}$, contra $32,1 \mathrm{U}^{\mathrm{m}} \mathrm{m}^{-1}$ encontrada por $\mathrm{CAMPOS}^{7,8}$. Outra possibilidade é a de que o teor de ácido ascórbico na água de coco deste experimento tenha sido maior do que na utilizada por Campos (concentração não determinada), ou seja, variações devido aos diferentes cultivares.

A Figura 4 representa os resultados da análise de atividade enzimática da peroxidase dos cinco lotes de água de coco.

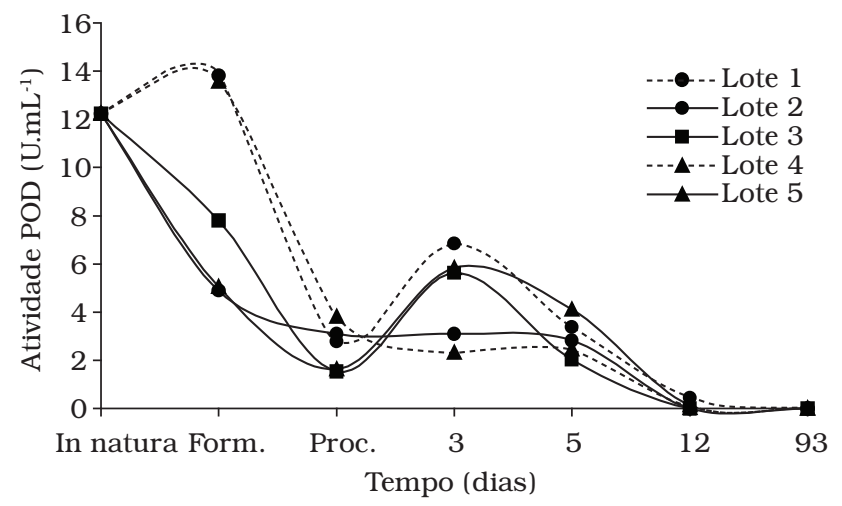

Figura 4. Atividade enzimática da Peroxidase (POD) da água de coco (Lote $1=138^{\circ} \mathrm{C} / 10$ segundos e sem adição de $\mathrm{AA}$; Lote $2=139{ }^{\circ} \mathrm{C} / 10$ segundos e $200 \mathrm{mg} \cdot \mathrm{L}^{-1}$ de AA; Lote $3=141{ }^{\circ} \mathrm{C} / 10$ segundos e $100 \mathrm{mg} . \mathrm{L}^{-1}$ de AA; Lote $4=144{ }^{\circ} \mathrm{C} / 10$ segundos e sem adição de AA; Lote $5=144{ }^{\circ} \mathrm{C} / 10$ segundos e $200 \mathrm{mg} \cdot \mathrm{L}^{-1}$ de AA; e AA = ácido ascórbico).

Conforme os resultados apresentados na Figura 4, observou-se que a adição de $100 \mathrm{mg} . \mathrm{L}^{-1}$ de AA causou uma redução de $36 \%$ na atividade da peroxidase (de 12,23 para 7,80 U.mL ${ }^{-1}$ ), e a adição de 200 mg. L $^{-1}$ causou cerca de $60 \%$ de redução (de 12,23 para 5,05 U.mL ${ }^{-1}$ ). CAMPOS ${ }^{7,8}$ observou que, com a adição de $100 \mathrm{mg} . \mathrm{L}^{-1}$ de AA ocorria uma redução de $74 \%$ da atividade da peroxidase na água de coco, enquanto 200 mg. L $^{-1}$ causavam 100\% de redução. Ou seja, a inativação encontrada foi menor do que a detectada por Campos. O aumento da sensibilidade do método e a baixa atividade enzimática da água de coco in natura, de 12,23 U.mL ${ }^{-1}$, em relação à que foi encontrada por Campos (114,3 U.mL $\left.{ }^{-1}\right)$, podem explicar esta diferença.

Observou-se atividade residual em todos os lotes e regeneração da enzima peroxidase na água de coco dos Lotes 1 , 3 e 5. Nos Lotes 2 e 4, após o tratamento térmico, ocorreu uma gradual perda de atividade de peroxidase até o $12^{\circ}$ dia de estocagem.

No Lote 5 foi observada intensa regeneração da peroxidase. Por ter sido processada na maior temperatura $\left(144^{\circ} \mathrm{C}\right)$, a água de coco deste lote deveria apresentar inativação maior do que a do Lote 2 , por exemplo, que foi processada a $139{ }^{\circ} \mathrm{C}$. Entretanto, o Lote 2 foi o que apresentou a maior inativação. A degradação do ácido ascórbico pode ter sido acelerada pela alta temperatura de processo atingida no Lote 5 , fazendo com que o ácido ascórbico perdesse a sua capacidade de inibidor enzimático, enquanto que no Lote 2 a temperatura menor pode ter possibilitado a maior estabilidade do AA, que funcionou como inibidor enzimático, resultando em menor escurecimento durante a estocagem.

O AA é altamente efetivo contra o escurecimento enzimático, devido a sua habilidade em reduzir as quinonas geradas por enzimas, retornando-as ao composto fenólico de origem, antes que elas possam iniciar futuras reações formadoras de pigmentos. Entretanto, ao mesmo tempo, o AA está sendo oxidado ao ácido dehidroascórbico (DHAA), ocorrendo a formação de compostos que causam o escurecimento. O DHAA também pode causar o escurecimento não-enzimático ${ }^{17,27,29}$.

Observou-se uma acentuada regeneração nos lotes com 100 e 200 mg.. -1 $^{-1}$ de ácido ascórbico e que foram processados nas temperaturas de 141 e $144^{\circ} \mathrm{C}$ (Lotes 3 e 5), contradizendo a lógica de que quanto maior a concentração de ácido ascórbico e maior a temperatura, maior deveria ser a inativação enzimática. Estes resultados sugerem que ocorre um certo sinergismo entre a ação destes dois parâmetros, ou seja, que existe um limite de temperatura para que o ácido ascórbico desempenhe sua função de antioxidante e inibidor enzimático durante a estocagem.

Segundo PONTIG e JOSLYN ${ }^{23}$, o ácido ascórbico pode ser oxidado por quatro sistemas: oxidação direta por oxidase ascorbato; por o-quinonas; por flavonas na presença de peroxidase e peróxido; por o-quinonas formadas pela mistura de catecol e polifenoloxidases e pelo sistema citocromo. Ou seja, além do tratamento térmico e das condições de estocagem, outros mecanismos podem ter contribuído para a degradação do ácido ascórbico, inclusive durante a determinação da atividade enzimática, visto que a água de coco apresenta a maioria dos componentes citados.

Ainda segundo PONTIG e JOSLYN ${ }^{23}$, a velocidade de degradação do ácido ascórbico na presença de peroxidase e peróxido de hidrogênio é de 0,36 mg/minuto, seguido de intenso escurecimento, quando foram analisados sucos de maçã com pH 3,75 e 6. Desta forma, durante a determinação da atividade da peroxidase, nos lotes de água de coco que tinham um grande residual de ácido ascórbico, o escurecimento pode ter ocorrido mais lentamente, não sendo detectado nos 10 minutos de análise, já quando o lote apresentava baixo residual de ácido ascórbico o escurecimento foi detectado mais rapidamente. As variações de oxigênio dissolvido, em cada embalagem, também podem ter influenciado os resultados, já que o ácido ascórbico seria inicialmente oxidado por ele.

Entretanto, a concentração de ácido ascórbico nos Lotes 2 e 5 eram semelhantes até o $12^{\circ}$ dia de estocagem. A menor estabilidade do ácido ascórbico, devido ao intenso tratamento térmico do Lote 5, pode ter acelerado o escurecimento durante as análises devido à ação da própria enzima, utilizando-o como substrato. Isto pode explicar também as variações de atividade enzimática entre as triplicatas analisadas.

Estas observações sugerem que, em estudos futuros serão necessários métodos de determinação de atividade enzimática 
mais sensíveis, e que não sofram interferências dos constituintes da amostra, como o ácido ascórbico. Portanto, seriam mais recomendados métodos que medissem o consumo dos substratos, como peróxido de hidrogênio, fenóis ou do próprio ácido ascórbico.

Em resumo, observou-se que quando a água de coco é submetida a tratamentos térmicos intensos e sem a adição de AA ocorre o seu imediato escurecimento. Entretanto, utilizando-se tratamentos térmicos acima de $140{ }^{\circ} \mathrm{C} / 10$ segundos, na presença de oxigênio dissolvido e atividade enzimática residual, o AA, quando adicionado, tende a sofrer degradação durante a estocagem, resultando em um gradual escurecimento da água de coco.

Testar novos binômios de tempo e temperatura e incluir modificações nas embalagens, como o uso de absorvedores de oxigênio, para reduzir a oxidação do ácido ascórbico, são questões que devem ser consideradas.

\section{Conclusões}

- Tratamentos térmicos de $138,139,141$ e $144{ }^{\circ} \mathrm{C}$ foram suficientes para a inativação da enzima polifenoloxidase da água de coco, com ou sem adição de ácido ascórbico;

- Tratamentos térmicos com temperaturas de 138 e $144^{\circ} \mathrm{C}$, sem adição de ácido ascórbico, conferem uma coloração rosada à água de coco imediatamente após a saída do trocador de calor e não são suficientes para total inativação da peroxidase;

- A maior estabilidade físico-química da água de coco foi alcançada com adição de 200 mg.L -1 $^{-1}$ de ácido ascórbico e tratamento térmico a $139{ }^{\circ} \mathrm{C}$ por 10 segundos, por manter o maior residual de ácido ascórbico após 93 dias de estocagem e, conseqüentemente, apresentar menor variação de cor; e

- O uso de ácido ascórbico na estabilização de água de coco esterilizada e acondicionada assepticamente mostrou-se promissor, contudo, mais estudos são necessários, visando adequar as condições de processo, para tornar o seu uso tão efetivo quanto o do metabissulfito.

\section{Agradecimentos}

Ao CNPq pela bolsa de doutorado, à Profa. Dra. Hélia Harumi Sato pela colaboração nas análises e discussão sobre atividade enzimática e à Fundação de Amparo à Pesquisa do Estado de São Paulo - FAPESP, por financiar a aquisição do sistema asséptico piloto.

\section{Referências bibliográficas}

1. ABREU, F. A. P. Extrator de água de coco verde. Embrapa Agroindústria Tropical. Comunicado Técnico, n. 34, p. 1-5, 1999a.

2. ABREU, F. A. P. Processo de conservação da água de coco por métodos combinados. Patente DEINPI/CE No 000129, Setembro, 1999b.

3. ABREU, L. F.; ARAUJO, A. V. C.; ARAUJO, E. A. F.; EL-AOUAR, A. A.; NEUMANN, D.; MORAIS, M. M. ; SILVA, M. A. A. P. Perfil sensorial e aceitabilidade de amostras de água de coco obtidas por diferentes processos de fabricação. Boletim do Centro de Pesquisa e Processamento de Alimentos, Curitiba, v. 23, n. 2, p. 397-412, 2005.

4. AGÊNCIA BRASIL. Água de coco do Brasil começa a ganhar o mundo. Entrevista em 17 mar. 2004. Disponível em: < http://www. netbabillons.com.br/bolsa/bolsa246.htm $>$ Acesso em: 30 jul. 2004.

5. BUCHNER, N. Aseptic processing and packaging of food particulates. In: WILLHOFT, E. M. A. Aseptic processing and packaging of particulates foods. Glasgow: Blackie Academic \& Professional, 1993. Chap. 1, p. 1-22.

6. CABRAL, L. M. C. estabilização da água de coco verde por meio de filtração com membranas. In: Aragão, W. M. COCO - Póscolheita. Brasília: Embrapa Informação Tecnológica, 2002. Cap. 7, p. 54-57.

7. CAMPOS, C. F. Desenvolvimento de processos térmico e químico para inativação enzimática e preservação do sabor da água de coco verde (Cocos nucifera L.). Belo Horizonte, 1993. 140 p. Dissertação (Mestre em Ciência de Alimentos), Faculdade de Farmácia, Universidade Federal de Minas Gerais (UFMG).

8. CAMPOS, C. F.; SOUZA, P. E. A.; COELHO, J. V.; GLÓRIA, M. B. A. Chemical composition, enzyme activity and effect of enzyme inactivation of flavor quality of green coconut water. Journal of Food Processing and Preservation, v. 20, n. 6, p.487-500, 1996.

9. CURSINO, M. M.; SABAA SRUR, A.; LOURENÇO, M.; PEREIRA, W. Contribuição à industrialização da água de coco (Cocos nucifera) verde. In: CONGRESSO BRASILEIRO DE CIÊNCIA E TECNOLOGIA DE ALIMENTOS, 15, 1996, Poços de Caldas. Anais...Poços de Caldas: SBCTA, 1996.

10. DATAMARK, BRAZIL TREND. Pesquisas e tendências de mercado, 2002.

11. DAVID, P. R. B. S.; FERNANDES, Z. F. Conservação de água de coco por refrigeração. Boletim do Centro de Pesquisa e Processamento de Alimentos, Curitiba, v. 16, n. 1, p. 1-12, jan/jun, 1998.

12. FAO, 2000. La FAO consigue la primera patente para hacer del agua de coco una bebida energetica para los deportistas. Comunicado de Imprensa 00/51. Disponível em: <http://www. fao.org/WAICENT/OIS/PRESS_NE/PRESSSPA/2000/prsp0051. htm> Acesso em: $11 \mathrm{dez} .2003$.

13. FARIA, J. A. F. Vida-de-prateleira de alimentos processados assepticamente. In: II SEMINÁRIO LATINO AMERICANO Avanços em tecnologia para o processamento e envasamento asséptico de alimentos. Campinas, 1993, p. 7-28.

14. FARIA, J. A. F. Processamento e envase asséptico. XII Prêmio Brasileiro de Embalagem - Troféu Embanews 2003. Revista Embanews, n. 152a, p. 30, 2003.

15. FARIA, J. A. F. Departamento de Tecnologia de Alimentos da Faculdade de Engenharia de Alimentos da Unicamp. Extrator de água de coco. Campinas: Unicamp, 2003.

16. GREGory, J. F. Vitamins. In: FENNEMA, O. R. Food Chemistry, 3 ed. New York: Marcel Dakker, Inc., 1996. Chap. 8, p. 531-616.

17. HENSHALL, J. D. Ascorbic acid in fruit juices and beverages. In: COUNSELL, J. N.; HORNING, D. H. Vitamin C (Ascorbic Acid). London: Applied Science Publishers, 1981, Cap. 8, p. 123-137.

18. HOLDSWORTH, S. D. Aseptic processing and packaging of food products. Elsevier Science Publisher Ltda. London, 1992, Chap. 9, p. 335-375. 
19. LEBER, A. S. L.; FARIA, J. A. F. Alterações microbiológicas em água de coco acondicionada em garrafas plásticas. Revista Higiene Alimentar, v. 18, n. 119, p. 55-58, 2004.

20. MINOLTA. Precise color communication. Manual. Minolta Co., Ltd. Osaka, 1994. 49 p.

21. NIELSEN, S. S.; MARCY, J. E.; SADLER, G. D. Chemistry of aseptically processed foods. In: CHAMBERS, J. V.; NELSON, P. E. (Eds.). Principles of aseptic processing and packaging. Chap. 5. Washington: The Food Processors Institute, 1993, 257 p.

22. PETRUS, R. R.; FARIA, J. A. F.; DELBEN, L. A. S. Avaliação de conformidade das condições operacionais de uma área limpa para envase asséptico. Higiene Alimentar, v. 17, n. 112, p. 22-30, 2003.

23. PONTING, J. D.; JOSLYN, M. A. Ascorbic acid oxidation and browing in apple tissue extracts. Archives of Biochemistry, v. 19 , p. $47-63,1948$.

24. RANIERI, M. Água de coco: um mercado em crescimento. Engarrafador Moderno, v. 74, p. 24-28, 2000.

25. REUTER, H. Processes for packaging materials sterilization and system requirements. In: REUTER, H. Aseptic Processing of Foods. $1^{\text {st }}$ ed. Hamburg: Technomic, 1988. Chap. 5, p. 155-165.
26. ROSA, M. F.; ABREU, F. A.P. Processos convencionais de conservação de água-de-coco. In: ARAGÃO, W. M. COCO - Póscolheita. Brasília: Embrapa Informação Tecnológica, 2002. Cap. 6, p. 42-53.

27. SAPERS, G. M. Browing of foods: control by sulfites, antioxidants, and other means. Food Technology, Oct., v. 47, n. 10 p. 75-84, 1993.

28. SILVA, M. F. V. Efeitos dos diferentes tratamentos e embalagens nas características da polpa de acerola e na determinação dos teores de ácido ascórbico e das antocianinas durante o armazenamento. Campinas, 1999, 224 p. Tese (Doutor em Tecnologia de Alimentos), Faculdade de Engenharia de Alimentos, Universidade Estadual de Campinas (UNICAMP).

29. VÁMOS-VIGYÁZÓ, L. Prevention of enzymatic browning in fruits and vegetables - A review of principles and practice. In: LEE, C. Y.; WHITAKER, J. R. Enzymatic browning and its prevention. Washington: American Chemical Society, 1995. Chap. 4, p. $49-62$.

30. WOSIACKI, G.; DEMIATE, J.M.; MELLO, F. Nata de coco - O estado da arte. Boletim da Sociedade Brasileira de Tecnologia de Alimentos, v. 30, n. 2, p. 142-155, 1996. 